\title{
A SEPARAÇÃO DOS PODERES E A POSSIBILIDADE DE ALTERAÇÃOO DO SISTEMA DE GOVERNO BRASILEIRO
}

\author{
THE SEPARATION OF POWERS AND POSSIBILITY OF AMENDMENT \\ OF THE BRAZILIAN GOVERNMENT SYSTEM
}

\section{RESUMO}

O presente estudo apresentará as principais características do parlamentarismo no contexto histórico brasileiro, a fim de analisar a constitucionalidade de uma possível alteração do atual sistema de governo presidencialista, tendo por base principalmente as vantagens do regime semipresidencialista como alternativa ao atual sistema, que, na realidade fática, acaba por estimular crises e a ausência de relações políticas transparentes, já que personaliza demais o poder na figura do Presidente e não mantém abertos canais formais de relacionamento democrático entre os Poderes.

Palavras-Chave: Parlamentarismo; Semipresidencialismo; Presidencialismo; Separação dos Poderes; Constitucionalidade

\begin{abstract}
This paper will present the main characteristics of parliamentarism in the Brazilian historical context, in order to analyze the constitutionality of a possible alteration of the current presidential system of government, based mainly on the advantages of the semi-presidential regime as an alternative to the current system, which, in fact, it turns out to stimulatecrises and the absence of transparent political relations, since it overly personalizes power in the figure of the President and does not maintain open channels of democratic relationship between the Powers.
\end{abstract}

Keywords: Parliamentarianism; Semi-presidentialism; Presidentialism; Separation of Powers; Constitutionality.

\footnotetext{
${ }^{1}$ Doutoranda em Direito do Estado na PUC-SP. Mestre em Direito Tributário na PUC-SP. Graduada em Direito pela Universidade Federal do Rio Grande do Norte - UFRN. Advogada.

${ }^{2}$ Mestre em Direito Administrativo e Doutor em Direito do Estado pela PUC/SP. Professor na Graduação e na PósGraduação stricto sensu (Mestrado e Doutorado) da PUC/SP. Presidente do Instituto CEDDE - Centro de Estudos de Direito e Desenvolvimento do Estado. Advogado.

${ }^{3}$ Mestranda em Direito Processual Civil pela PUC/SP. Advogada.
} 


\section{INTRODUÇÃO}

O cenário político atual aliado ao recente impeachmentnos faz pensar a respeito do nosso sistema de governo presidencialista, afinal, assistimos (perplexos) notados esforços para se manter o equilíbrio entre os poderes institucionalizados no país.

Consideramos, assim, válidos os esforços científicos e acadêmicos no sentido de se pensar o presidencialismo brasileiro - como e em que direção podemos aperfeiçoá-lo- de maneira a garantir (ou tentar garantir) maior transparência e equilíbrio do Poder Executivo diante dos demais poderes.

Nesse sentido é que nos propomos a estudar a constitucionalidade de uma possível alteração do sistema de governo presidencialista brasileiro, pela via do semipresidencialismo.

\section{PRINCIPAIS CARACTERÍSTICAS DO PARLAMENTARISMO NA ATUALIDADE}

Para a total e completa compreensão do sistema semipresidencialista, inicialmente, deve se ter em mente as principais características do parlamentarismo, uma vez que referido sistema combinado com o presidencialismo contribuiu para o aprimoramento das regras do semipresidencialismo.

Segundo Bianchini (2014, p. 65-66), ajustificativa mais antiga do parlamentarismo reside no fato de que:

[...]o povo, numa autêntica comunhão, é que deveria tomar as decisões, como fazia originalmente quando todos os membros da comunidade ainda podiam se reunir sob a grande tília da aldeia.Mas por motivos práticos, é impossível fazer perguntas a cada um deles sobre detalhes insignificantes [...]. É por isso que nos valemos, sensatamente, da ajuda de uma comissão eleita de pessoas confiáveis, o que se constitui, afinal, no Parlamento".

A principal característica do parlamentarismo, portanto, está consolidada na representatividade do povo pelo Parlamento.

Ainda que existam variações entre os países que adotam o sistema, pode-se afirmar, em linhas gerais, que o parlamentarismo também se caracteriza (i) pela "distinção entre Chefe de Estado e Chefe de Governo"; (ii) pela "Chefia do governo com responsabilidade política"; i) pela "possibilidade de dissolução do Parlamento" (DALLARI, 2007, p. 235-239).

Com relação à distinção entre Chefe de Estado e Chefe de Governo, vale destacar que, no parlamentarismo, o Chefe de Estado será o monarca ou o Presidente da República e terá função 
preponderantemente de representação do Estado, não participando das decisões políticas. Já o Chefe de Governo exerce o poder executivo e, assim, possui papel político central.

No que se refere à "Chefia do governo com responsabilidade política", o Chefe do Governo pode ser demitido pelo Parlamento a qualquer momento, seja em razão da "queda do governo" (e consequente perda da maioria parlamentar) ou pelo "voto de desconfiança".

Sobre o tema Dalmo de Abreu Dallariadverte o seguinte:

"Num sistema bipartidário, quando se realizam eleições para o Parlamento, a chefia do governo está sempre em jogo. Se o partido a que pertence o Primeiro Ministro conseguir manter a maioria parlamentar, ele permanece no cargo. Se, pelo contrário, o maior número de cadeiras for conquistado por outro partido, este, automaticamente, adquire a chefia do governo, devendo ser escolhido entre os seus membros o novo Primeiro Ministro"(DALLARI, 2007, p. 239).

Já o "voto de desconfiança" é apresentado por um parlamentar em caso de não concordância, no todo ou em parte, quanto à política desenvolvida pelo Primeiro Ministro.

$\mathrm{Na}$ hipótese de o voto de desconfiança ser aprovado com maioria parlamentar, isso revela que o Chefe de Governo contraria a vontade da maioria parlamentar e, portanto, o próprio povo, a quem os parlamentares representam.

Já a“possibilidade de dissolução do Parlamento" poderá ser diferenciada de acordo com o tipo de sistema partidário adotado: se bipartidário ou pluripartidário.

No sistema bipartidário, a dissolução do Parlamento ocorre quando Primeiro Ministro nota que possui pequena maioria e que as eleições de novos parlamentares gerarão uma ampliação desta maioria.

No sistema pluripartidário a dissolução do Parlamento é mais comum e ocorre quando o Primeiro-Ministro, ante um voto de desconfiança, entende que o Parlamento possui entend , , diverso do povo.

Nesta hipótese, o Primeiro-Ministro pode pedir ao Chefe de Estado para declarar extintos os mandatos dos parlamentares e determinar novas eleições. Após as eleições, caso o PrimeiroMinistro tenha a maioria parlamentar, continuará no cargo, caso não tenha, será destituído.Tais características essenciais do parlamentarismo podem ser entendidas como os freios e contrapesos necessários à manutenção da separação dos poderes, que também é uma das características que dá suporte ao regime parlamentarista (FERREIRA FILHO, 1993, p. 107). 


\section{BREVES COMENTÁRIOS ACERCA DO PARLAMENTARISMO NO CONTEXTO HISTÓRICO BRASILEIRO}

No contexto histórico brasileiro, o parlamentarismo foi adotado tão somente por duas vezes: a primeira, no Segundo Império (o conhecido Parlamentarismo às avessas), e a segunda na República, logo após a renúncia de Jânio Quadros.

A primeira experiência parlamentarista foi oficializada duas décadas após a antecipação da maioridade de D. Pedro II (em 02 de dezembro de 1825), através do Decreto $\mathrm{n}^{\circ}$ 523, de 20 de julho de 1847, que instituiu a Presidência do Conselho de Ministros, que conferiu à Constituição Política do Império brasileiro de 1824 uma leitura parlamentarista.

A partir de tal regime parlamentarista eram estabelecidos quatro poderes: Legislativo, Executivo, Judiciário e Moderador.

Note-se aqui a forte influência das ideias de Benjamin Constant, que diferentemente da tripartição de poderes de Montesquieu (Legislativo, Executivo e Judiciário), adotava a citada divisão segundo quatro Poderes, cabendo especialmente ao Poder Moderador a manutenção de uma relação harmônica e equilibrada dos outros três Poderes (FERREIRA FILHO, 1993, p. 107).

À Assembleia Geral bicameral, compreendida pela Câmara dos Deputados e um Senado, cabia o exercício do Poder Legislativo.

Neste cenário, os Deputados eram eleitos, através de voto censitário, para o exercício de um mandato de 4 (quatro) anos. Já os Senadores possuíam cargos vitalícios e eram escolhidos pelo Imperador, a partir de uma lista tríplice prevista no sistema eleitoral.

Vale dizer ainda que a Câmara dos Deputados poderia ser dissolvida a qualquer momento ante o exercício do Poder Moderador pelo Imperador, que exercia assim tanto o Poder Executivo quanto o Poder Moderador, conforme se verifica dos artigos 98 e 102 daquela Constituição. ${ }^{4}$

Tendo em mente o Poder Moderador, o Imperador acaba por possuir papel central e não o Parlamento.

Neste sentido, inclusive, são as lições deManoel Gonçalves Ferreira Filho:

\footnotetext{
${ }^{4}$ Art. 98. O Poder Moderador é a chave de toda a organização Política, e é delegado privativamente ao Imperador, como Chefe Supremo da Nação, e seu Primeiro Representante, para que incessantemente vele sobre a manutenção da Independência, equilíbrio, e harmonia dos mais Poderes Políticos;Art. 102. O Imperador é o Chefe do Poder Executivo, e o exercita pelos seus Ministros de Estado.
} 


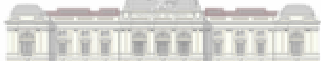

REVISTA ACADEIVICA

Faculdade de Direito do Recif

Vol.92 N.01 - Anno CXXIX

Em face disso, a experiência no Império era a de que a confiança do Imperador e não a do Parlamento era essencial para o Gabinete. O Parlamento podia desaprovar o Gabinete, votar contra ele, mas a última palavra era a do Imperador. Se este pretendesse manter o Gabinete contra a maioria parlamentar, bastava-lhe dissolver a Câmara que o Gabinete sairia da eleição posterior com a maioria conveniente. (FERREIRA FILHO, 1993, p. 69).

Deste modo, tendo por base o Poder Moderador, e a total submissão do Parlamento às vontades do Imperador, o parlamentarismo às avessas sequer poderia ser compreendido como um sistema parlamentarista, na sua essência.

Já o regime parlamentarista, adotado logo após à renúncia de Jânio Quadros, a partir da Emenda Constitucional $\mathrm{n}^{\mathrm{o}} 4$ (de 2 de setembro de 1961, conhecida como Ato Adicional), possuía, desde seu início, caráter de expediente, o que fez com que o sistema nascesse já ferido de morte.

A adoção do parlamentarismo em questão visava limitar os poderes do vice de Jânio Quadros, João Goulart, que não possuía aprovação dos setores militares e políticos, visto sua aproximação a uma posição que era compreendida como esquerdista.

Além disso, vale ressaltar que a Emenda Constitucional $n^{0}$ 4/61 também previa um plebiscito sobre a manutenção do parlamentarismo ou a volta do sistema presidencial, que seria realizado nove meses após o fim do mandato presidencial (ou seja, em abril de 1965). Todavia, foi antecipado para janeiro de 1963 e teve resultado favorável ao presidencialismo.

A ausência de êxito do regime parlamentarista em 1963 deve-se principalmente ao fato de que as normas editadas pela Emenda $n^{\circ}$ 4/61 eram demasiado complexas e exigentes, o que foi fator predominante para criar óbice à investidura dos Gabinetes, aprovação do Presidente do Conselho, aprovação do próprio Conselho.Como também bem assinala Manoel Gonçalves Ferreira Filho: "Essa experiência parlamentarista não teve tempo para mostrar seja as qualidades, seja os defeitos do regime"(FERREIRA FILHO, 1993, p. 73).

Após as duas experiências de parlamentarismo no Brasil, narradas anteriormente, vale ter em mente que, em 21 de abril de 1993, ocorreu novo plebiscito, visando a escolha do sistema de governo do país.Tal plebiscito ocorreu logo após a redemocratização do país e, segundo os termos do artigo $2^{\circ}$ do ADCT, a votação ocorreu quanto às seguintes opções:“a forma (república ou monarquia constitucional) e o sistema de governo (parlamentarismo ou presidencialismo) que 
devem vigorar no País". Como é de vasto conhecimento,prevaleceua forma republicana e o sistema presidencialista.

\section{POSSIBILIDADE DE ALTERAÇÃO DO SISTEMA DE GOVERNO BRASILEIRO}

Quanto à temática em questão, cabe analisar se eventual Proposta de Emenda Constitucional visando alteração do sistema de governo brasileiro, atualmente o presidencialista, para o parlamentarismo (ou outro sistema, como o semipresidencialista) seria inconstitucional por violação do artigo $60, \S 4^{\circ}$, III da Constituição Federal ${ }^{5}$.

Vale ressaltar que, de fato, não se pode admitir qualquer alteração constitucional que atente à "separação dos poderes", visto que deve ser encarada como cláusula pétrea, segundo os termos do já citado do artigo $60, \S 4^{\circ}$, III da Carta Magna.

Neste sentido, também vale ressaltar que a Constituição Brasileira, em seu artigo $2^{\circ}$, adverte que "são Poderes da União, independentes e harmônicos entre si, o Legislativo, o Executivo e o Judiciário".

A partir do texto constitucional, seria inconstitucional a alteração normativa que, de alguma forma, viesse a agredir a separação entre os poderes Legislativo, Executivo e Judiciário.

Assim, é notória a intenção do constituinte originário no sentido de criar mecanismo constitucional que inviabilize regimes ditatoriais, nos quais duas ou até mesmo as três de tais funções acabam por se concentrar em um único órgão ou uma pessoa.

Todavia, a alteração do sistema de governo em si, não pode ser encarada comc una violação à separação dos poderes.

Schimitt fixa expressamente a ideia de que o regime parlamentar, de natureza liber $\quad \mathrm{n}$ como essência a diversidade e o conflito de opiniões na busca de seus objetivos, apoiando-se igualmente na publicidade e na separação de poderes como necessários ao seu desempenho. (Bianchini, 2014, p. 86)

Quanto ao tema, o artigo $2^{\circ}$ do ADCT previu plebiscito para que fosse definida "a forma (república ou monarquia constitucional) e o sistema de governo (parlamentarismo ou

\footnotetext{
${ }^{5}$ Art. 60. A Constituição poderá ser emendada mediante proposta:

(...)

$\S 4^{\circ}$ Não será objeto de deliberação a proposta de emenda tendente a abolir:

I - a forma federativa de Estado;

II - o voto direto, secreto, universal e periódico;

III - a separação dos Poderes;

IV - os direitos e garantias individuais.
} 
presidencialismo) que devem vigorar no País". E em tal plebiscito, como é de conhecimento amplo e geral, o povo brasileiro optou pela forma republicana e pelo sistema presidencialista.

Entretanto, ainda que se verifique o esgotamento da eficácia da norma constante do artigo $2^{\circ}$ do ADCT, não se pode admitir a inviabilidade de alteração do sistema de governo, quando respeitada a tripartição dos poderes.

Isto porque, a sociedade humana é dinâmica não podendo estar engessada em um único sistema de governo.

Além disso, a Constituição, no parágrafo único do artigo $1^{\circ}$, dispõe que "todo o poder emana do povo".

Desta forma, à luz da soberania popular, seria constitucional a edição de Proposta de Emenda Constitucional contemplando novo plebiscito para que o povo exerça seu poder de cidadania e escolha entre os seguintes sistemas de governo: (i) presidencialismo; (ii) parlamentarismo e, aqui, pode ser incluído, a nosso ver, o (iii) semipresidencialismo.

A dificuldade de implementação do sistema parlamentarista no cenário brasileiro atual brasileiro decorre principalmente da multiplicidade de partidos. ${ }^{6}$

Neste sentido, é de extrema pertinência o quanto apresentado por Dalmo de Abreu Dallari:

Isso contribuiu para que se firmasse a praxe de escolher para Primeiro-Ministro sempre um representante da maioria parlamentar, condicionando-se sua permanência no cargo à manutenção dessa maioria. Essa prática foi facilitada pelo caráter bipartidário do sistema britânico, pois esta circunstância dá condições a que um único partido possa deter a maioria das cadeiras(DALLARI, 2007, p. 235).

Assim, é evidente que a adoção do parlamentarismo no Brasil dependeria de rrande reforma partidária, pois o parlamentarismo pressupõe, para sua estabilidade, um partidário estável, seja bipartidário (Grã-Bretanha), seja bipolar (Alemanha, e, na medida em que se pode falar de parlamentarismo na França, esta última), ou não terá estabilidade(FERRI FILHO, 1993, p. 107).

Ante o pluripartidarismo brasileiro, flagrante que os primeiros-ministros e os Gabinetes teriam vida efêmera, gerando maior instabilidade e, assim, menor governabilidade.

\footnotetext{
${ }^{6}$ Note-se que, na Inglaterra, ainda que existam atualmente vários partidos formalmente constituídos, as disputas eleitorais têm se mantido, na prática, entre dois partidos principais (o Partido Conservador e o Partido Trabalhista).
} 


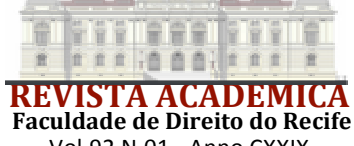

Vuldade de Direito do Recife

Vol.92 N.01 - Anno CXXIX

Além disso, também há que se falar na existência de elemento psicológico atrelado ao fato de que a população brasileira está acostumada com a eleição direta do presidente da República.

Assim, a adoção do parlamentarismo - em que o Chefe do Estado seria escolhido indiretamente pelo Parlamento - provavelmente seria interpretado como uma afronta à democracia.

É, neste cenário, portanto, que o semipresidencialismo se apresenta como uma proposta mais viável.

Isto porque, uma das principais vantagens do semipresidencialismo se configura na combinação de elementos do presidencialismo com o parlamentarismo, a partir de mecanismos de freios e contrapesos que lhe são próprios.

Um destes mecanismos se refere à possibilidade de o presidente nomear o primeiroministro, que deverá ter governabilidade a partir de uma boa aprovação frente ao Parlamento.

Sobre a temática,Marcelo Leonardo Tavares observa que o semipresidencialismo apresenta uma dinâmica própria, inclusive dando respaldo a saídas menos traumáticas em caso de crises:

De um lado, combina traços do presidencialismo (como o exercício de algumas atribuições de política interna pelo presidente e seu poder de organizar o Governo) e do parlamentarismo (como a responsabilidade colegiada do Governo perante o Parlamento e a dualidade do Executivo). De outro lado, sua base normativa estimula relações dinâmicas próprias na atuação preventiva em eventuais choques entre o Executivo e o Legislativo. (TAVARES, 2017, p. 5978)

Portanto, o regime semipresidencialista seria vantajoso como alternativa ao atual sistema presidencialista, que, na prática, acaba por se comportar "como uma fábrica de crises: não estimula relações políticas transparentes; personaliza demais o poder na figura do Presidente e não mantém abertos canais formais de relacionamento democrático entre os Po " (TAVARES, 2017, p. 78).

No presidencialismo brasileiro, o presidente depende da maioria da base parlament $\varepsilon$ que tenha governabilidade, o que se tornaria nitidamente mais fácil quando há poucos partidos.

Todavia, quando a base parlamentar partidária está pulverizada, o Chefe de Governo precisa lançar mão de instrumentos políticos informais para conseguir governar com eficiência. 
Deste modo, é notório que qualquer reforma política no Brasil deve começar por aprimorar regras partidárias e eleitorais, principalmente no que se refere à necessária redução da quantidade de partidos políticos.

Ante todo o cenário traçado anteriormente, o semipresidencialismo seria uma vantagem ao permitir que o presidente, eleito diretamente pelo povo e Chefe do Estado, nomeie o primeiroministro, para exercer a função de Chefe de Governo.

No semipresidencialismo, também poderia ser facultado ao Parlamento a possibilidade de demitir o primeiro-ministro.

Assim, em que pese o presidente, na teoria, ser livre para a nomeação do primeiroministro, certo é que, na prática, deverá ter cautela e apresentar nome que seja majoritariamente aceito na base parlamentar.

Também seria possível que, em tal sistema semipresidencialista, houvesse a dissolução do Parlamento pelo Chefe do Estado e que a responsabilidade política do Chefe de Estado se processasse perante o Legislativo, contemplando possibilidade de destituição do presidente pelo impeachment.

Entretanto, importa frisar que, nada obstante o semipresidencialismo estimular um relacionamento institucional mais transparente e uma excelente sistemática de freios e contrapesos, a sua adoção neste momento de crise (posterior ao recente impeachment), poderia contribuir ao seu agravamento.

Assim, a alteração para o sistema semipresidencialista depende não só de aprovação do Congresso Nacional, como também da população (através de plebiscito, como citado anteriormente), o que certamente dificulta a sua implementação na atualidade, marcada não só pelo pluripartidarismo na base parlamentar, como também por uma população nitidamente dividida em posições antagônicas.

Todavia, nada obstante os empecilhos, certo é que a adoção do semipresidencialismo se configura, no mínimo, como uma boa ideia na tentativa de mitigar alguns dos probleı le governabilidade sofridos no presidencialismo presente no Brasil da atualidade.

Por fim, como bem observado por Manoel Gonçalves Ferreira Filho, lembrando a sabedoria popular, de que Roma não se fez num dia e toda caminhada começa por um primeiro passo:"preciso, entretanto, dar esse primeiro passo na direção correta. Eis aqui uma possibilidade de direção"(FERREIRA FILHO, 1993, p. 110).

\section{CONCLUSÕES}


Ante o cenário atual, conclui-se que o presidencialismo da atualidade não tem se mostrado satisfatório enquanto sistema de governo.

Já a adoção do parlamentarismo - em que o Chefe de Governo seria escolhido indiretamente pelo Parlamento - provavelmente seria interpretado pelo povo como uma ameaça à democracia.

Neste sentido, como abordado anteriormente, o semipresidencialismo pode ser visto como uma proposta mais viável.

Vale lembrar que a alteração para o sistema semipresidencialista depende não só de aprovação do Congresso Nacional, como também da população (através de plebiscito), o que pode se configurar como um empecilho para sua implementação, tendo em vista não só o pluripartidarismo na base parlamentar, como também posições políticas antagônicas no seio da sociedade brasileira.

Nada obstante as dificuldades práticas para a adoção do semipresidencialismo, vale ressaltar que tal sistema pode ser entendido como uma boa opção para se mitigar alguns dos problemas de governabilidade sofridos no presidencialismo da atualidade.

\section{REFERÊNCIAS}

BIANCHINI, Fernando Novelli. Democracia representativa sob a crítica de Schmitt e democracia participativa na apologia de Tocqueville. Campinas, SP: Millenium Editora, 2014.

BOBBIO, Norberto; MATTEUCCI, Nicola; PASQUINO, Gianfranco.Dicionário de política. Tradução: Carmen C. Varrialeet al. Brasília: Editora Universidade de Brasília, 1998. v. 1.

DALLARI, Dalmo de Abreu.Elementos de teoria geral do Estado. 27.ed. São Paulo: Saraiva, 2007.

FERREIRA FILHO, Manoel Gonçalves. O Parlamentarismo. São Paulo: Saraiva, 1993.

SCHMITT, Carl. Situação intelectual do sistema parlamentar atual. São Paulo: Página Aberta Ltda., 1996.

TAVARES, Marcelo Leonardo. Semipresidencialismo no Brasil: por que não?Revista de Informação Legislativa, Brasília ano 54, n. 215, jul./set. 2017. 